\title{
Correlation between charring rate and oxygen permeability for 12 different wood species
}

Received: December 12, 2005 / Accepted: May 8, 2006 / Published online: July 28, 2006

\begin{abstract}
The charring rates of 12 different wood species originating from Europe and the tropics with densities ranging from 350 to $750 \mathrm{~kg} / \mathrm{m}^{3}$ were investigated to obtain clues on their fire resistance behavior. This was done by measuring the thickness of the charred layer after a 30-min exposure to the standard fire ISO 834-1. No correlation was observed between charring rate and density. In search of another physical property that could be used as an indicator of fire resistance, the oxygen permeabilities of the selected wood types were measured. A strong correlation between oxygen permeability perpendicular to the wood fiber direction and charring rate was found, which is quite straightforward given that oxygen is the necessary component to enable smoldering and ignition, both affecting the charring rate. It seems that oxygen permeability is potentially more suitable as a parameter to evaluate the fire resistance of char-sensitive wooden constructions, rather than density. No general preference of the tree ring orientation from $0^{\circ}$ (tangential) to $45^{\circ}$ and $90^{\circ}$ (radial) was found for these measurements.
\end{abstract}

Key words Oxygen permeability $\cdot$ Charring rate $\cdot$ Wood species $\cdot$ Fiber orientation $\cdot$ Fire resistance

\section{Introduction}

Wood is a commonly used building material appreciated for its various properties. One of these is good load-bearing capacity under fire impact, which depends on the charring rate of the wood. Due to the thermal screening by the charred layer, the uncharred wood remains at moderate

E. Hugi $(\varangle) \cdot$ M. Wuersch $\cdot$ K. Ghazi Wakili

Building Technologies, Materials Science and Technology, Empa,

Duebendorf CH-8600, Switzerland

Tel. +41-44-823-4977; Fax +41-44-823-4154

e-mail: erich.hugi@empa.ch

W. Risi

Wood Laboratory, Materials Science and Technology, Empa,

Duebendorf CH-8600, Switzerland temperatures even in a long-lasting fire. Consequently the charring rate is the most important property of wood with respect to fire resistance and fire integrity. Particularly for applications in door frames or door leaves, where a rather thin layer of wood is installed as the room closure, the charring rate directly influences the amount of deformation and hence the possibility of openings leading to failure in fire resistance tests. The previous Swiss Standard ${ }^{1}$ for fire resistance of materials included a list of 13 different wood species declared as appropriate to be used as door frames or door leaf frames due to their density being at least $500 \mathrm{~kg} /$ $\mathrm{m}^{3}$. This enabled the mutual substitution of the listed wood species without requiring the repetition of the fire resistance test for the whole door system. This changed at the beginning of 2005 when the Swiss regulative board introduced new fire safety regulations, which refer to the harmonized European standards. ${ }^{2-4}$ These allow any wood type that fulfils the fire resistance test but does not allow interchange of the wooden parts.

Numerous investigations on parameters influencing the charring rate of wood have been carried out during the past decade. Some such as Mikkola ${ }^{5}$ have suggested simple models including density, wood moisture content, air oxygen concentration, and heat flux as parameters influencing the charring rate and used the cone calorimeter method for model validation. A linearly decreasing correlation between the charring rate and the density was reported by Njankouo et al. ${ }^{6}$ A closer analysis of the tabulated values showed a weak correlation as the coefficient of determination was only $r^{2}=0.4$ where $0 \leq r^{2} \leq 1$. Others such as White, ${ }^{7}$ Lingens et al., ${ }^{8}$ and Frangi and Fontana ${ }^{9}$ found no correlation between density and the charring in the range of 350$750 \mathrm{~kg} / \mathrm{m}^{3}$ as well as no correlation between charring rate and wood moisture content in the range of $8 \%-15 \%$ (typical for wood in buildings). In a recent review article, Babrauskas ${ }^{10}$ reported that high density timber products without any gaps or joints, when under postflashover room fires, will char at similar rates found in fire resistance tests, namely at $0.5-0.8 \mathrm{~mm} / \mathrm{min}$. Out of these considerations the Swiss Association of Door Manufacturers (VST) became interested in investigating parameters that are strongly cor- 
related to the fire resistance of a large variety of wood species of both central European and tropical origin. This led to the present study, which was carried out at Empa resulting in a diploma thesis at the School of Architecture, Civil, and Wood Engineering in Biel/Switzerland by Wuersch. ${ }^{11}$ In the research work, different parameters of wood with an assumed impact on its fire resistance were examined. They were partitioned in primary parameters (density, oxygen permeability, and fiber orientation) and secondary parameters resulting from fire tests (charring rate, deflection, temperature increase) using specially developed equipment. The purpose was to determine if any correlation existed among the above parameters, which could be used as an indicator for future classification with respect to the fire resistance of wooden door systems.

\section{Experimental}

Two different experiments were carried out for each of the 12 selected wood species (Table 1). First, the charring rate measurements were carried out in the Empa small horizontal furnace. Figure 1 gives a view on the opening of the furnace and its ventilation hood. For each of the 12 wood species, three specimens of $1000 \times 90 \times 45 \mathrm{~mm}$ were cut differing in their tree ring orientation. The visible tree ring orientation made an angle of $0^{\circ}$ (tangential cut), $45^{\circ}$, and $90^{\circ}$ (radial cut), respectively, with the surface of the sample facing the furnace. All samples were conditioned for 3 weeks in a climate chamber at $20^{\circ} \mathrm{C}$ and $60 \%$ relative humidity. These special sizes were used because of the minimum required dimensions of door or door leaf frames when a fire resistance time of $30 \mathrm{~min}$ has to be achieved. The exposure to unilateral fire load took place according to the standardized temperature-time curve ISO 834-1. ${ }^{12}$ The samples were arranged in a special sample holder and equipped with displacement transducers on their unexposed side to investigate deflections primarily induced by loss of moisture, which is not discussed here and will be the subject of a future publication. After a fire exposure of $30 \mathrm{~min}$, the charring rate was measured by removing the samples, cooling them with water, cutting five slices of 5 -mm thickness from each specimen, abrading the char

Table 1. Summary of the measured values for density, charring rate, oxygen permeability index (OPI), and moisture content of the 12 investigated wood species

\begin{tabular}{|c|c|c|c|c|c|}
\hline Wood species & $\begin{array}{l}\text { Tree ring } \\
\text { orientation }\end{array}$ & $\begin{array}{l}\text { Density } \\
\left(\mathrm{kg} / \mathrm{m}^{3}\right)\end{array}$ & $\begin{array}{l}\text { Charring } \\
\text { rate } \\
(\mathrm{mm} / \mathrm{min})\end{array}$ & $\begin{array}{l}\text { Oxygen } \\
\text { permeability } \\
\text { index }\end{array}$ & $\begin{array}{l}\text { Moisture } \\
\text { content } \\
(\% \text { w } / w)\end{array}$ \\
\hline Abachi & $0^{\circ}$ & 435.6 & 0.726 & 9.85 & 9.0 \\
\hline Triplochiton & $45^{\circ}$ & 478.0 & 0.750 & 9.26 & 9.5 \\
\hline scleroxylon & $90^{\circ}$ & 446.6 & 0.757 & 9.58 & 9.6 \\
\hline Abura & $0^{\circ}$ & 575.2 & 0.791 & 9.57 & 5.8 \\
\hline \multirow[t]{2}{*}{ Hallea ciliata } & $45^{\circ}$ & 555.7 & 0.818 & 9.73 & 5.8 \\
\hline & $90^{\circ}$ & 539.6 & 0.752 & 9.63 & 5.3 \\
\hline Maple & $0^{\circ}$ & 601.5 & 0.690 & 10.11 & 9.0 \\
\hline \multirow[t]{2}{*}{ Acer pseudoplatanus } & $45^{\circ}$ & 600.3 & 0.639 & 9.64 & 9.3 \\
\hline & $90^{\circ}$ & 615.0 & 0.623 & 9.76 & 10.1 \\
\hline Beech & $0^{\circ}$ & 744.9 & 0.564 & 10.30 & 10.0 \\
\hline \multirow{2}{*}{ Fagus sylvatica } & $45^{\circ}$ & 664.0 & 0.703 & 10.08 & 10.2 \\
\hline & $90^{\circ}$ & 685.2 & 0.700 & 10.15 & 11.4 \\
\hline Oak & $0^{\circ}$ & 659.5 & 0.557 & 10.77 & 11.3 \\
\hline \multirow[t]{2}{*}{ Quercus robur } & $45^{\circ}$ & 646.1 & 0.571 & 10.78 & 8.0 \\
\hline & $90^{\circ}$ & 572.7 & 0.544 & 10.75 & 10.3 \\
\hline Ash & $0^{\circ}$ & 713.9 & 0.613 & 9.97 & 12.0 \\
\hline \multirow{2}{*}{ Fraxinus excelsior } & $45^{\circ}$ & 566.3 & 0.681 & 10.36 & 7.3 \\
\hline & $90^{\circ}$ & 560.8 & 0.640 & 10.26 & 7.3 \\
\hline Spruce & $0^{\circ}$ & 419.8 & 0.582 & 10.15 & 9.1 \\
\hline \multirow{2}{*}{ Picea abies } & $45^{\circ}$ & 422.0 & 0.573 & 10.15 & 8.8 \\
\hline & $90^{\circ}$ & 420.1 & 0.568 & 10.26 & 8.8 \\
\hline Koto & $0^{\circ}$ & 598.3 & 0.651 & 9.79 & 6.0 \\
\hline Pterygota & $45^{\circ}$ & 640.4 & 0.636 & 9.70 & 6.0 \\
\hline macrocarpa & $90^{\circ}$ & 615.3 & 0.629 & 9.88 & 4.0 \\
\hline Meranti dark red & $0^{\circ}$ & 655.4 & 0.515 & 10.72 & 15.4 \\
\hline \multirow[t]{2}{*}{ Shorea ssp. } & $45^{\circ}$ & 625.5 & 0.519 & 10.72 & 16.1 \\
\hline & $90^{\circ}$ & 644.8 & 0.528 & 10.53 & 16.9 \\
\hline \multirow{3}{*}{$\begin{array}{l}\text { Meranti light red } \\
\text { Shorea ssp. }\end{array}$} & $0^{\circ}$ & 620.4 & 0.570 & 10.60 & 16.7 \\
\hline & $45^{\circ}$ & 592.4 & 0.533 & 10.60 & 15.6 \\
\hline & $90^{\circ}$ & 586.9 & 0.580 & 10.43 & 16.7 \\
\hline \multirow{3}{*}{$\begin{array}{l}\text { Sipo } \\
\text { Entandophragma } \\
\text { utile }\end{array}$} & $0^{\circ}$ & 677.0 & 0.499 & 10.84 & 9.0 \\
\hline & $45^{\circ}$ & 722.7 & 0.511 & 11.12 & 9.0 \\
\hline & $90^{\circ}$ & 716.8 & 0.492 & 10.72 & 9.0 \\
\hline \multirow{3}{*}{$\begin{array}{l}\text { Fir } \\
\text { Abies alba }\end{array}$} & $0^{\circ}$ & 364.7 & 0.796 & 9.52 & 7.5 \\
\hline & $45^{\circ}$ & 389.3 & 0.624 & 9.91 & 7.5 \\
\hline & $90^{\circ}$ & 388.0 & 0.709 & 9.83 & 8.0 \\
\hline
\end{tabular}




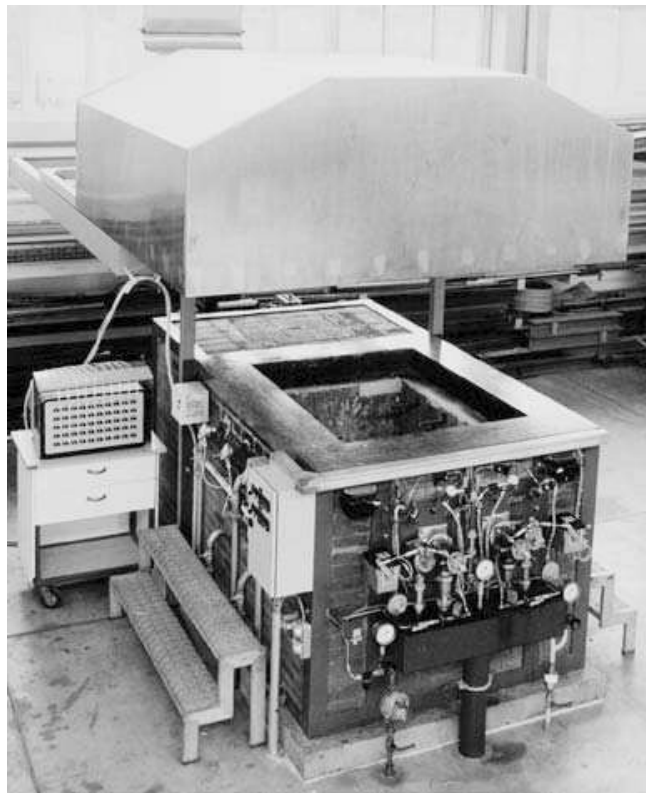

Fig. 1. The small horizontal furnace of Empa with an exposed area of $1.0 \times 0.8 \mathrm{~m}$ where samples of $1.25 \times 1.05 \mathrm{~m}$ size can be subjected to the standard fire ISO 834-1
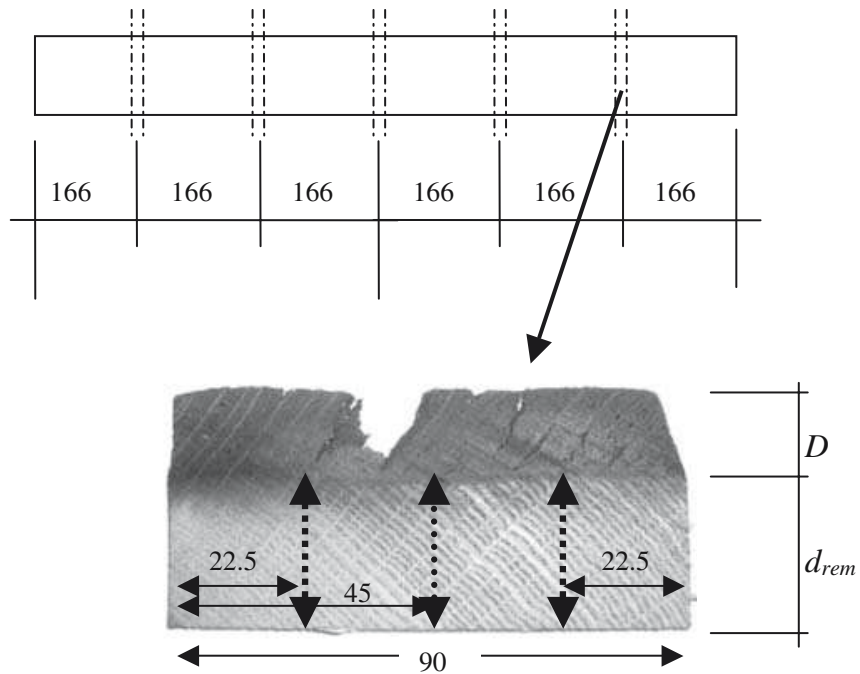

Fig. 2. Five slices of $5 \mathrm{~mm}$ in thickness were cut out of each sample after fire exposure. One of them with the 3 sites of charring depth measurement is shown enlarged (sizes in $\mathrm{mm}$ )

layer, and comparing the resulting thickness (Fig. 2) with that of the initial sample. In other words, the remaining (uncharred) thickness $d_{\text {rem }}$ was determined by averaging over 15 sites for each specimen.

$\beta=\frac{D}{t}=\frac{d_{\text {init }}-d_{\text {rem }}}{t}$

where $D$ is the charred thickness $(\mathrm{mm}), d_{\text {init }}$ is the initial thickness $(\mathrm{mm}), d_{\mathrm{rem}}$ is the remaining (uncharred) thickness $(\mathrm{mm}), t$ is time ( $\mathrm{min})$, and $\beta$ is the charring rate $(\mathrm{mm} / \mathrm{min})$.

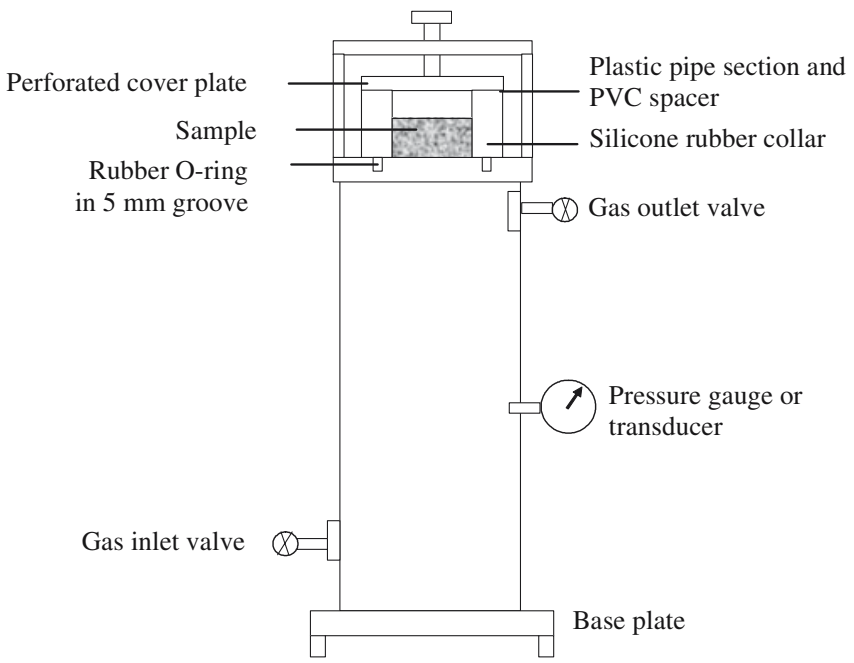

Fig. 3. Apparatus for measuring the oxygen permeability index (OPI)

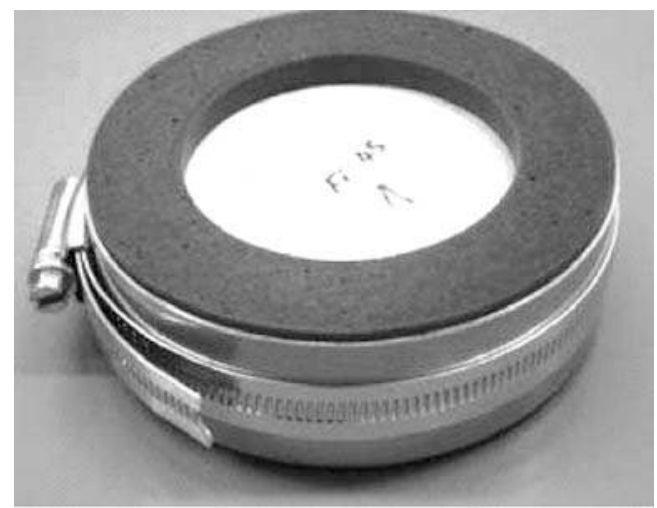

Fig. 4. Special sample holder for OPI measurement

The permeability to oxygen perpendicular to the wood fiber direction was measured next at room temperature by means of a test method that was originally developed by Beushausen et al. ${ }^{13}$ for concrete specimens and was adapted by the authors for wood specimens. The test method involved measurement of the pressure decay of oxygen passing through a $25-\mathrm{mm}$-thick slice of a $68-\mathrm{mm}$-diameter core of wood (Fig. 3). The sample holder included a hose clamp to guarantee tightness of the whole assembly as shown in Fig. 4. In the test, the samples were initially subjected to oxygen at a pressure of $100 \mathrm{kPa}$ and the pressure decay with time was monitored. The coefficient of permeability was determined from the slope of the line produced when the natural logarithm of the ratio of the initial pressure to the instantaneous pressure was plotted against time. The oxygen permeability index (OPI) is defined as the negative logarithm of the coefficient of permeability.

$k=\frac{\omega \cdot V \cdot g \cdot d}{R \cdot A \cdot \theta \cdot t} \times \ln \frac{P_{0}}{P(t)}$

$\mathrm{OPI}=-\log _{10}(k)$ 


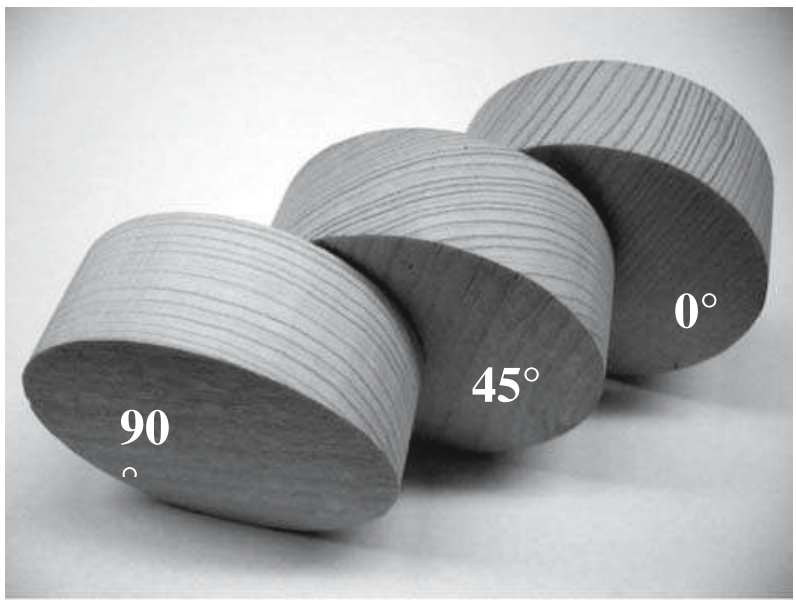

Fig. 5. The small test specimens for the measurement of OPI in the three fiber directions

where OPI is the oxygen permeability index, $k$ is the coefficient of permeability of the test sample $(\mathrm{m} / \mathrm{s}), \omega$ is the molar mass of gaseous oxygen $(32 \mathrm{~g} / \mathrm{mol}), V$ is the volume of the pressure cylinder $\left(\mathrm{m}^{3}\right), g$ is gravitational acceleration $\left(9.81 \mathrm{~m} / \mathrm{s}^{2}\right), R$ is the universal gas constant $(8.313 \mathrm{Nm} / \mathrm{K}$ $\mathrm{mol}), A$ is the sample cross section $\left(\mathrm{m}^{2}\right), d$ is the sample thickness $(\mathrm{m}), \theta$ is absolute temperature $(\mathrm{K}), t$ is time $(\mathrm{s}), P_{0}$ is the pressure at the start of the test $(\mathrm{kPa})$, and $P(t)$ is the pressure at time $t(\mathrm{kPa})$.

For each of the 12 wood species, two series of three specimens of the aforementioned sizes but different tree ring orientations of $0^{\circ}, 45^{\circ}$, and $90^{\circ}$ with respect to the specimen surface were cut out of the bulk (Fig. 5). All specimens were cut out of a bulk of $2.5 \times 0.09 \times 0.045 \mathrm{~m}$ of the corresponding wood type and kept 3 weeks under standard conditions for wood, i.e., $20^{\circ} \mathrm{C}$ and $60 \%$ relative humidity, prior to testing.

\section{Results}

The measured charring rates of all wood samples are represented as a function of measured density and tree ring orientation (Fig. 6) and as a function of measured oxygen permeability index and tree ring orientation (Fig. 7). In both figures, the orientation of the indicated, and the samples of the same wood type are connected by dotted lines. A summary of the measured values for density, charring rate, and oxygen permeability index (OPI) is given in Table 1.

\section{Discussion}

According to Fig. 6, there is no correlation between the charring rate and the density for the investigated range of $350-750 \mathrm{~kg} / \mathrm{m}^{3}$. Looking in the $x$ - and $y$-directions of Fig. 6 , the influence of tree ring orientation on density and char-

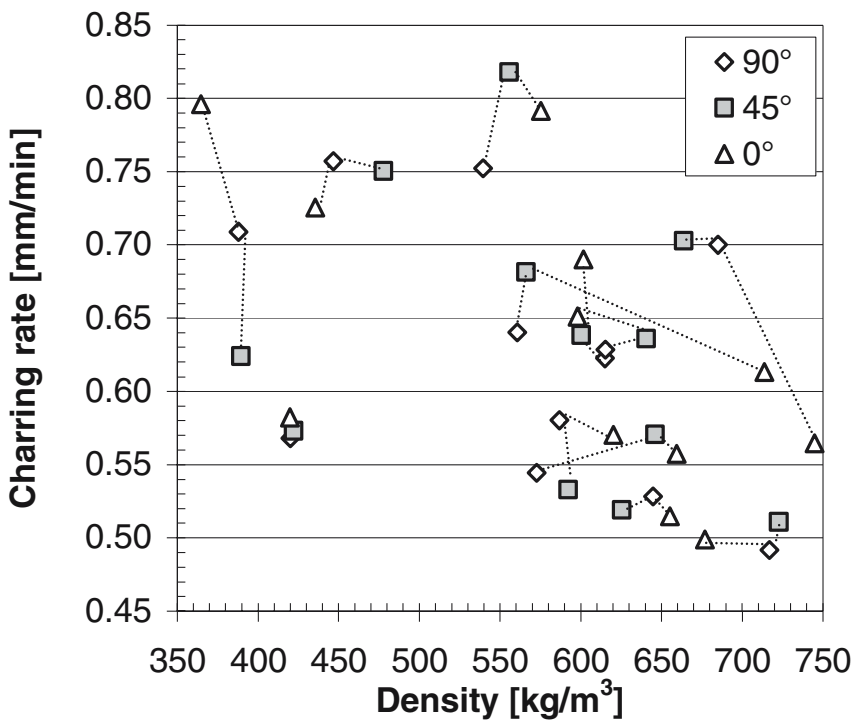

Fig. 6. Charring rate as a function of density and tree ring orientation. Samples of the same wood species are connected by dotted lines

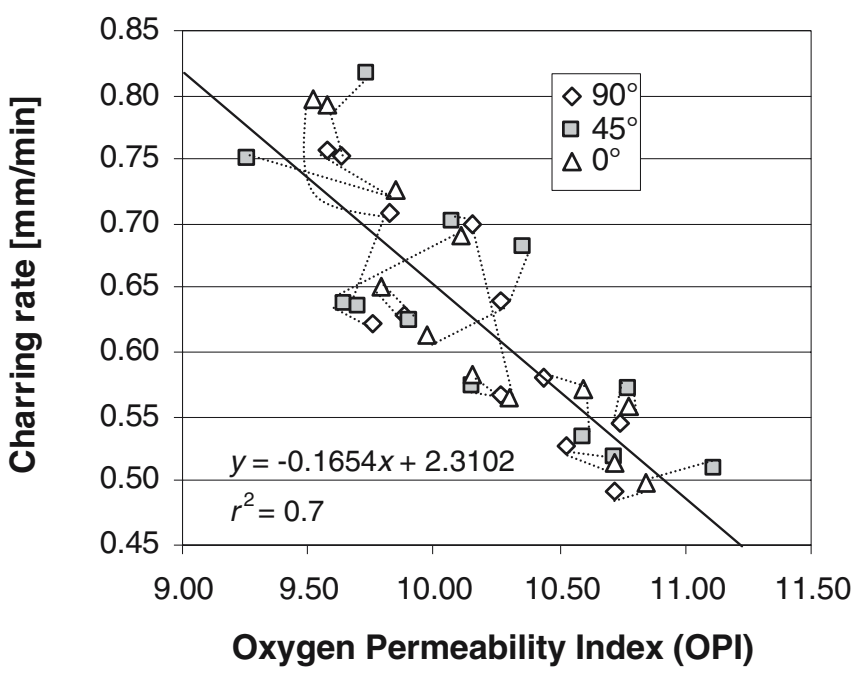

Fig. 7. Charring rate as a function of OPI and fiber orientation. Samples of the same wood species are connected by dotted lines. A linear regression is also shown

ring rate, respectively, seems to be unique for each wood type. For some, the dispersion is only in density, while for others is in the charring rate so that no general tendency is detectable. Figure 7 on the contrary, shows a strong correlation between the charring rate and the oxygen permeability index (OPI). Looking in the $x$-direction of Fig. 7, no correlation between the tree ring orientation of the wood samples and their oxygen permeability index is observed. The coefficient of determination resulting from an applied linear regression gives a quite promising value $\left(r^{2}=0.70\right)$. A possible explanation of this behavior is that during fire exposure a gradient of oxygen concentration will emerge from the char front (oxygen sink) toward the fire as well as the room side. As the char layer itself consumes oxygen for 
completing pyrolysis, the oxygen supply originates mainly from the room side. Deviations in Fig. 7 from the main tendency cannot be due to moisture content (Table 1) because for oak, which has a high moisture content, the charring rate was higher than expected, and for koto, which has a lower water content, the charring rate was lower than expected (Table 1). With the charring rates of the same wood type with different fiber orientations being located on both sides of the regression line, a tendency depending on softwood or hardwood as stated by Harada ${ }^{14}$ cannot be confirmed.

To obtain more information on the influence of oxygen permeability on the fire resistance behavior of different wood species, further investigations on sealed samples (the room side only) and on fire-induced mechanical deformations are planned. This will also be helpful in the validation of wood combustion modeling at different levels of sophistication as proposed by Bruch et al. ${ }^{15}$

Acknowlesdgments The authors express their gratitude to the entire staff of the Fire Laboratory, Empa, for their support with the experimental work, W. Trindler for providing access to the OPI apparatus, D. Heer of the Wood Laboratory, Empa, for sample preparation, and K. Richter and E. Pöhler for helpful discussions. This study received financial support from the Swiss Association of Door Manufacturers (VST).

\section{References}

1. SIA/Lignum (1997) Brandschutz im Hochbau. SIA Dokumentation 83, Zurich

2. European Standard EN 1363-1 (1999) Fire resistance tests part 1: general requirements. CEN Central Secretariat, Brussels
3. European Standard EN 1634-1 (2000) Fire resistance tests for doors and shutter assemblies part 1: fire doors and shutters. CEN Central Secretariat, Brussels

4. European Standard EN 13501-2 (2002) Fire classification of construction products and building elements part 2: classification using data from fire resistance tests, excluding ventilation services. CEN Central Secretariat, Brussels

5. Mikkola E (1990) Charring of wood (in Finnish). VTT Research Report 689, Espoo

6. Njankouo JM, Dotreppe JC, Franssen JM (2004) Experimental study of the charring rate of tropical hardwoods. Fire Mater 28:1524

7. White RH (2000) Charring rate of composite timber products. In: Proceedings of wood and fire safety (part one), 4th international scientific conference, May 14-19, 2000. Zvolen, Slovak Republic, pp 353-363

8. Lingens A, Windeisen E, Wegener G (2005) Investigating the combustion behaviour of various wood species via their fire gases. Wood Sci Technol 39:49-61

9. Frangi A, Fontana M (2003) Charring rates and temperature profiles of wood sections. Fire Mater 27:91-102

10. Babrauskas V (2005) Charring rate of wood as a tool for fire investigation. Fire Safety J 40:528-554

11. Wuersch M (2005) Klassierungssystemzum Brandverhalten verschiedener Holzarten. Diploma Thesis N r. F/4/375/05/0, School of Architecture, Civil and Wood Engineering, Biel, Switzerland

12. International Standard ISO 834-1 (1999) Fire resistance tests elements of building construction part 1: general requirements. Geneva

13. Beushausen HD, Alexander MG, Mackechnie J (2003) Concrete durability specifications in an international context. BFT Concrete Plant Precast Technol 7:22-32

14. Harada T (1996) Charring of wood with thermal radiation. 2. Charring rate calculated from mass loss rate. Mokuzai Gakkaishi 42:194-201

15. Bruch C, Peters B, Nussbaumer T (2003) Modelling wood combustion under fixed bed conditions. Fuel 82:729-738

The publication of this article was made possible by an Emachu Research Fund. The authors are grateful for the fund. 